\title{
A forma e o infinito, de Diderot a Baudelaire
}

\section{Marcelo Jacques de Moraes}

Resumo: A noção de infinito em Baudelaire remete à vocação de uma coisa para intensificar-se, isto é, para alterar-se e transformar-se em si mesma pela mediação de uma forma. A partir daí, pretendo discutir a importância do infinito baudelairiano para pensar como a forma estética encena sua própria historicidade. A questão é trabalhada em contraponto com a reflexão estética de Diderot. Palavras-chave: Baudelaire, Diderot, infinito.

Abstract: Baudelaire's notion of infinity refers to experience's propensity to intensify itself, that is, to alter and transform itself in itself through the mediation of form. From there I intend to think about the importance of the Baudelairian infinity as a means to discuss the relationship between experience and the aesthetical form, and the way the latter enacts its own historicity. In the paper, the Baudelairian infinity is contrasted with Diderot's reflection on aesthetics. Keywords: Baudelaire, Diderot, infinity. 
Para empreender esta breve reflexão sobre "A forma e o infinito, de Diderot e Baudelaire", parto de uma perspectiva conceitual que, no âmbito da reflexão histórica, implica necessariamente uma perspectiva anacrônica.

Em primeiro lugar, nada se afirma como totalidade idêntica a si mesma por si só, em sua solidão material, instantânea. O próprio reconhecimento de uma coisa como tal, que permite, aliás, que seja concebida como forma autônoma, deriva de uma operação de distanciamento, de construção de um lugar-entre, lugar entre o que, dessa coisa, se mostra e a predicação com que é mostrada. Ou seja: uma coisa só vem a ser ela própria na aproximação com outra coisa, aproximação que a torna simultaneamente igual a e diferente de si própria: só se reconhece um pela mediação de outro, e essa alteridade constitutiva de toda identidade não permite que uma coisa persevere em sua unidade consigo mesma. Pois essa dimensão relacional da identidade não implica apenas remissão ininterrupta, em via de mão dupla, da coisa uma à coisa outra com que ela se diz, ela implica também uma espécie de proximidade distante, de estranha familiaridade entre o mesmo e o outro, lugar que virtualiza a um só tempo o sentido e sua suspensão: lugar de passagem e de impasse.

Assim, para irmos rápido, todo esse processo implica que cada forma, ao ser apresentada como tal, em sua tensão, em seu índice de heterogeneidade constitutivo, se atualiza ao mesmo tempo em que se inscreve virtualmente na história e se projeta virtualmente no futuro, potencializando-se, então, como "um objeto de tempo complexo, de tempo impuro: uma extraordinária montagem de tempos heterogêneos formando anacronismos".

Não é o caso de desenvolver essa perspectiva aqui, mas, como se verá, algo dela se depreenderá da leitura que esboçarei aqui de Diderot e Baudelaire.

Em Baudelaire, para chamar de imediato um deles, a noção de infinito remete justamente à vocação de uma coisa de aproximar-se mais de si mesma por meio da correspondência com seus outros, o que se potencializa, justamente, por meio de sua apresentação estética: de sua mise-en-forme, que é sempre mise-en-correspondance... Nas palavras de Michel Deguy, poeta e ensaísta contemporâneo que é grande leitor de Baudelaire: "[...] infinitizar é redobrar de intensidade; tornar-se mais o mesmo; por meio da correspondência, uma relação recontraída, reatada, com seu outro, ou comparação. Há perfumes frescos-como-carnes-de-crianças".2

DIDI-HUBERMAN. Devant le temps. Histoire de l'art et anachronisme des images. Paris: Minuit, 2000, p. 16.

"[... infinitiser, c'est redoubler d'intensité; devenir plus le même; par la correspondance, une relation recontractée, renouée, avec son autre, ou comparaison. Il est des parfums frais-comme-des-chairs-d'enfants." Quando não 
Infinitizar é, pois, pôr em ação a virtualidade de tudo o que há de intensificar-se, isto é, de transformar-se em si mesmo e, ao mesmo tempo, alterar-se pela mediação de uma linguagem, de uma forma, justamente, afirmando-se e dispondo-se assim como unidade - "uma tenebrosa e profunda unidade", dirá Baudelaire. ${ }^{3}$ Trabalho infinito que projeta o presente de onde sempre se fala - e que inarredavelmente também se fala por meio dessa forma -, trabalho que projeta o presente no tempo por vir de sua metamorfose... E que assim aponta também, e antes de tudo, para a infinita espessura formal desse presente, jamais apreensível em sua totalidade imperfeita (já que, encontrando-se sempre em estado de esboço, ${ }^{4}$ como veremos, jamais se perfaz). Assim, o presente tornado passado sob a mediação de uma forma jamais se consuma, encontra-se em permanente metamorfose ou formação (flerto aqui com o sentido freudiano do termo, que implica justamente a temporalidade complexa sempre em questão...) - em permanente intensificação, espessamento, infinitização. Daí a expressão ambígua, paradoxal, que encontramos em $O$ pintor da vida moderna: ${ }^{5}$ "a memória do presente". ${ }^{6}$

Para Baudelaire, portanto, o infinito não se reduz, como em certa tradição que se consolida para os contemporâneos do poeta, a uma aproximação do verdadeiro na linha do tempo, conforme o sentido que lhe dava a ideologia do progresso, tão pregnante nesta segunda metade do século XIX, e segundo a qual o conhecimento era um processo cumulativo e o mundo estava em desenvolvimento constante na direção das luzes, no rumo de um futuro cada vez mais pleno. O infinito implica antes essa espessura virtual a toda experiência do presente, e que a imaginação deve materializar em uma forma. Para Baudelaire, cabe especialmente à arte abrir esse infinito, permitir que o presente funcione como multiplicador de sentidos complexos e imprevisíveis, que, ao se materializarem em formas, possam, por sua vez, disseminar-se, permitindo trazer ao presente atual esse presente tornado passado em sua "qualidade essencial de presente": como memória, justamente, e como memória impura, exatamente por sua infinita espessura...

houver outra referência, a tradução das passagens citadas é minha. DEGUY, Michel. Choses de la poésie et affaire culturelle. Paris: Hachette, 1986, p. 36-7.

[...] une ténébreuse et profonde unité." BAUDELAIRE, Charles. As flores do mal. Edição bilíngue. Trad. de Ivan Junqueira. Rio de Janeiro: Nova Fronteira, 1985, p. 114-5.

4 Sabe-se a importância que Baudelaire vai dar ao esboço. Cf. particularmente a seção "L'art mnémonique", em Le peintre de la vie moderne (Oeuvres complètes. Paris: Seuil, 1968, p. 555-6).

Que devemos ler nos dois sentidos que o duplo genitivo permite. 
Pois o infinito baudelairiano não é um infinito linear, um infinito que se definiria simplesmente pela negação do finito pertencente ao presente, cuja realização residiria sempre no futuro. Ao contrário, o infinito baudelairiano se manifesta na irremissível impureza de tudo o que há, em sua vocação para a estranheza, para a alteridade, no que poderíamos chamar de a carne viva do real. Para dar um exemplo bastante conhecido, eu poderia citar o poema "Uma carniça”, no qual, descrevendo em detalhes "uma carniça infame" em seu processo de putrefação, o poeta põe em cena a multiplicação na decomposição, a fecundidade na corrupção, o movimento na imobilidade, o infinito no finito; em suma, a metamorfose - isto é, a vida, no sentido mais pleno da palavra - na morte. E essa multiplicidade irredutível, paradoxalmente, encontra-se a ponto de se deixar apreender num quadro:

As formas se apagavam e nada mais eram senão um sonho,

Um esboço, lento de vir,

Sobre a tela esquecida, e que o artista acaba

Apenas pela lembrança.

Les formes s'effaçaient et nétaient plus qu'un rêve,

Une ébauche lente à venir,

Sur la toile oubliée, et que l'artiste achève

Seulement par le souvenir?

É interessante notar como o poeta, narrando a metamorfose das formas reais em formas "sobre tela", faz da arte o lugar em que a metamorfose é apreendida como tal, isto é, como tensão irresoluta entre o mesmo e o outro. Experiência cujo sentido é fato de "lembrança", de memória, justamente, mais do que de percepção. De toda maneira, a forma estética mostra que o instante não se encerra em si mesmo como queria, em seus primórdios, a fotografia, esta outra ilusão de posteridade que seria demolida menos de um século mais tarde. Nada o exprime melhor do que estes versos citados que, encenando o tempo da metamorfose das formas da carniça, prolongado ao infinito pelo imperfeito do verbo, desconcertam qualquer confinamento temporal, qualquer identidade do instante: “Les formes s'effaçaient et nétaient plus qu’un rêve,/ Une ébauche lente à venir...”. A forma estética definida pela metamorfose explicita-se, assim, como a apreensão deste instante paradoxalmente espesso, em 
que o passado ainda não se dissolveu e em que o futuro já se destaca (ao contrário do presente vazio do romântico Musset, por exemplo, para quem o passado já não existe mais e o futuro ainda não existe...). Nesse sentido, a forma estética constitui a explicitação da incontornável vocação da matéria do presente para a expansão - "a expansão das coisas infinitas" de que fala o soneto "Correspondências". ${ }^{8}$ É, pois, na e pela mise-en-forme da metamorfose em ação do presente que o infinito se desvela como possibilidade de um presente que não cessa de se desfazer e se refazer. Que precisa desfazer-se, para, paradoxalmente, se constituir. Que só se torna pensável na qualidade de experiência como construção - de memória...

A noção de infinito já se impunha, contudo, à discussão estética francesa desde o Iluminismo, particularmente com a reflexão estética de Diderot. Mas se a obra do escritor-filósofo-enciclopedista do século XVIII permite conceber a noção de presente como puro lugar de passagem, lugar em que contingências historicamente produzidas se encontram em permanente dissolução em prol do devir, da alteridade - o mundo que nos cerca seria, pois, um mundo de formas em sucessão -, ela não explicita essa sua infinita espessura (ainda que, na perspectiva anacrônica que contamina nosso olhar retroativo, não possamos não vê-la em latência: assim, colocando-a aqui em correspondência com esse seu outro que é a obra de Baudelaire, espessaremos um pouco alguns aspectos da obra de ambos).

Voltemos, pois, ao século xviII. Como sabemos todos, trata-se fundamentalmente de um século de crise. Num mundo cada vez mais cosmopolita e consciente de sua própria historicidade, em que já não mais se controlam totalmente opiniões e consciências, começa a firmar-se o sujeito autônomo moderno, este sujeito pretensamente esclarecido que pretende recusar todo e qualquer conhecimento que não tenha obtido por si próprio, que aspira a excluir-se da ordem social vigente para nela mais vigorosamente intervir.

Nesse sentido, um dos aspectos mais importantes do Iluminismo do século XVIII foi o de tentar sistematizar e propagar a perspectiva crítica do conhecimento em meio ao processo cada vez mais dispersivo e cada vez mais sôfrego de assimilação da infinitude heterogênea do mundo. Tal voracidade pode ser ilustrada pela proliferação de imagens no processo de apropriação do mundo: pinta-se, desenha-se e grava-se na ambição de catalogar todo o universo visível. Essas imagens, que visam ao conhecimento, buscam, 
contudo, de acordo com a tradição herdada do Renascimento, o genérico, o modelo ideal, descartando o detalhe específico, individual, que elas pensam como desvio.

Mas a reflexão crítica dos iluministas acabou por colocar em dúvida essa ideia tão cara ao pensamento clássico de uma natureza equilibrada, modelar, perfectível por sua própria vocação. Dúvida que Jean Starobinski, emprestando sua voz ao homem do século XVIII, formula nos seguintes termos: "E se não houvesse abstrato da natureza? Se a natureza fosse o concreto e nada além do concreto?".9

Em face de uma tradição que queria ver na natureza a tendência à regularidade e à perfeição, Diderot se destacará, em particular, por contrapor seu poder de variação, de divergência, de fermentação, de individuação. A ideia de natureza e a necessidade do recolhimento à Rousseau devem, pois, ser pensadas como a possibilidade de legitimar a crítica aos valores da cultura, ao saber constituído e compartilhado pelos contemporâneos, e não como algo da ordem de uma nostalgia concreta em relação à suposta harmonia de uma sociedade primitiva etc. ${ }^{10}$

É associado a essa vocação crítica que o conceito de gênio será apresentado na Enciclopédia de Diderot e d'Alembert como um dom natural, que, no caso específico das artes, o ensino acadêmico, por definição prescritivo, só podia inibir.

E ainda que a concepção de gênio de Diderot se transforme ao longo de suas obras, algo se mantém constante: mais do que sua vocação demiúrgica, que viria a prevalecer numa certa tradição romântica, o que caracteriza o gênio é a perspectiva crítica em relação ao senso comum, a qual, no limite, põe em questão o poder institucional e político que perpetua a transmissão tradicional de valores - papel que, na França do século XVIII, no campo das artes plásticas, é exercido pela Academia de pintura e escultura. Aliás, parece-me que já é possível inferir em Diderot a consciência moderna - de que Baudelaire seria o grande disseminador quase um século mais tarde - que concebe o artista como uma espécie de testemunha de seu presente ou, mais do que isso, como aquele que produz um olhar sobre esse presente, um olhar que ao mesmo tempo o afirma e dele destoa. Um exemplo: em seu Salão de 1765, Diderot exorta os jovens pintores para que deixem de imitar as obras do Louvre para alcançar o espaço público e observar a história em movimento:

STAROBINSKI, Jean. L'invention de la liberté. Genève: Skira, 1994, p. 117-8.

Como diz Luc Ferry, "o estado de natureza só foi inventado pelos filósofos com uma preocupação crítica que já anuncia o gesto revolucionário: trata-se, antes de mais nada, não de uma reconstrução fantasmática ... [...], mas sim precisamente de uma hipótese fictícia sem a qual a legitimidade do poder, ocultada que está pelo reino da tradição que sempre a declara já resolvida, não poderia sequer ser levantada". (FERRY Luc. Homo Aestheticus: a invenção do gosto na era democrática. São Paulo: Ensaio, p. 34). 
Meus amigos, há quanto tempo desenhais? Dois anos. Pois bem! É mais que suficiente. Abandonai essa oficina de maneira. [...] Buscai as cenas públicas; sede observadores nas ruas, nos jardins, nos mercados, nas casas, e obtereis ideias precisas sobre o movimento real das ações e da vida. ${ }^{11}$

E se, para o crítico de arte que é Diderot, é possível conceber um modelo ideal derivado do modelo mental de uma época, o destino desse modelo, evidentemente, é o de, ao fixar-se, desvanecer-se pela ação do gênio, ou corromper-se, pela imitação servil... Daí a invocação de Diderot neste mesmo texto ao estado de barbárie, mostrando uma vez mais que a recusa da civilização é menos a possibilidade de retorno a uma vida mais simples e feliz do que a condição da crítica do estado presente essencialmente histórico - da natureza humana. Ele termina a passagem em questão dizendo justamente que "o retorno ao estado de barbárie" é

[...] a única condição para que os homens convencidos de sua ignorância possam decidir-se pela lentidão do tateamento; os outros permanecem medíocres precisamente porque nascem, por assim dizer, sábios. Servis, e quase estúpidos imitadores daqueles que os precederam, estudam a natureza como perfeita, e não como perfectível. ${ }^{12}$

Estamos, portanto, diante de um mundo virtual, aberto, mundo dos possíveis, com vocação para a alteridade. Como diz o filósofo: "Certas vezes, a incredulidade é o vício de um tolo e a credulidade o defeito de um homem de espírito. O homem de espírito vê longe, na imensidão dos possíveis; o tolo não vê como possível senão o que é". ${ }^{13}$

É essa natureza mutante da matéria viva - e não uma essência metafísica qualquer, que residiria para além da aparência sensível das coisas -, é essa tensão mutante,

"Mes amis, combien y a-t-il que vous dessinez là? Deux ans. Eh bien! C'est plus quill ne faut. Laissz-moi cette boutique de manière. [...]. Cherchez les scènes publiques; soyez observateurs dans les rues, dans les jardins, dans les marchés, dans les maisons, et vous y prendrez des idées justes du vrai mouvement dans les actions de la vie." DIDEROT, Denis. Oeuvres esthétiques. Paris: Dunod, 1994, p. 671.

12 "[...] la seule condition où les hommes convaincus de leur ignorance puissent se résoudre à la lenteur du tâtonnement; les autres restent médiocres précisément parce quills naissent, pour ainsi dire, savants. Serviles, et presque stupides imitateurs de ceux qui les ont précédés, ils étudient la nature comme parfaite, et non comme perfectible." Idem. Ruines et Paysages. Salon de 1767. Paris: Hermann, 1995, p. 69-71.

(Grifo meu.) "Lincrédulité est quelquefois le vice d'un sot, et la crédulité le défaut d'un homme d'esprit. L'homme d'esprit voit de loin dans l'immensité des possibles; le sot ne voit guère de possible que ce qui est." Idem. Oeurres philosophiques. Paris: Garnier, 1961, p. 28.

Teresa revista de Literatura Brasileira [12|13]; São Paulo, p. 373-383, 2013 • 379 
diríamos nós, que a engenhosidade humana, encarnada, por exemplo, pelo ceticismo inventivo de um escritor como Diderot, é essa tensão que se deve imitar e materializar através de formas.

Mas é na interação - ou, melhor dizendo, no embate - permanente com o outro - mais do que numa interioridade relativamente inefável - que a perfectibilidade humana encontra sua expressão mais plena. E aí o filósofo deixa novamente de ser precursor de um certo romantismo. Pois o ceticismo de Diderot em relação à linguagem parece levar, não a um subjetivismo inescapável, mas à legitimação da palavra do outro como ponto de partida de um diálogo que não cessa de recomeçar. Como filósofo e como crítico, o escritor incorpora a linguagem do outro à sua (nesse sentido o projeto da Enciclopédia, em sua realização, permanece emblemático), problematizando-a, ao passo que, como ficcionista - notadamente em Jacques o fatalista ${ }^{14}$-, encena tal processo de incorporação.

Mas é também fundamental notar que o escritor parecia já intuir que o grande obstáculo a seu trabalho de enciclopedista não residia tanto nas diferenças de visão de seus colaboradores quanto na própria natureza da linguagem. Em vez de mediar a aproximação de um real supostamente inteligível através do estabelecimento de conceitos e representações estáveis e claramente remissíveis a outros conceitos e representações, a linguagem parece adiar a aquisição de certezas filosóficas ou práticas. Estas, de fato, não cessam de se perder no redemunho dos artigos e das pranchas da Enciclopédia:

Vimos, à medida que trabalhávamos, a matéria estender-se, a nomenclatura obscurecer-se [...] e os numerosos desvios de um labirinto inextricável se complicando cada vez mais. Vimos o quanto custava para nos assegurarmos de que as mesmas coisas eram as mesmas e quanto, também, para nos assegurarmos de que outras que pareciam diferentes não eram diferentes. ${ }^{15}$

Abordei o tema a partir do romance no artigo "O grande pergaminho de Diderot e o poder da linguagem". Sofia. Revista do Departamento de Filosofia da Universidade Federal do Espírito Santo. Vitória: UFES, ano VIII, n. 8, 2001.2.

"Nous avons vu, à mesure que nous travaillions, la matière sétendre, la nomenclature s'obscurcir, [...] et les détours nombreux d'un labyrinthe inextricable se compliquer de plus en plus. Nous avons vu combien il en coûtait pour s'assurer que les mêmes choses étaient les mêmes, et combien, pour s'assurer que d'autres qui paraissaient très différentes n'étaient pas différentes." DIDEROT, Denis. Encyclopédie ou dictionnaire raisonné des sciences, des arts et des métiers, tome II. Textes choisis et présentés par Alain Pons. Paris: Flammarion, 1986.

380 - MORAES, Marcelo Jacques de. A forma e o infinito, de Diderot a Baudelaire 
Assim, se a potência da linguagem era, a princípio, uma potência de concentração de sentidos - a Enciclopédia, nesse sentido, é mais uma vez exemplar: todo o conhecimento, de A a Z, numa única obra -, ela se tornava antes, aos olhos de Diderot, uma potência de dispersão - e de disseminação - de sentidos, que produzia formas instáveis, lugares de passagem e de impasse, para retomar os termos do início...

Desse modo, a "verdadeira Enciclopédia", em última instância, não poderia ser senão um texto por escrever, esse texto que, em Jacques o fatalista, é encarnado pelo grande metatexto "escrito lá em cima", para retomar o bordão do "grande pergaminho", de que Jacques se serve para apontar o imponderável do sentido de tudo o que se apresenta, seu eterno estado de devir. Como diz o valete, logo no início do romance:

[...] não sabemos o que está escrito lá em cima, não sabemos o que queremos, nem o que fazemos; não sabemos se seguimos nossa fantasia que se chama razão ou se seguimos nossa razão que, frequentemente, é somente uma fantasia perigosa que ora termina bem, ora termina mal. ${ }^{16}$

Recordemos, antes de voltar rapidamente a Baudelaire para concluir, a célebre conclusão dos Éléments de physiologie, um dos últimos textos do escritor: "O que percebo? Formas? Formas e mais o quê? Formas. Ignoro a coisa. Passamos por entre sombras, sombras nós mesmos para os outros e para nós". ${ }^{17}$

Bem, para concluir retomando a perspectiva propriamente baudelairiana do infinito, poderíamos confrontar essa transitoriedade cega e irreversível concebida por Diderot (com muitas ambiguidades, como tentei apontar) - modalidade do infinito linear que se opõe a uma modalidade teleológica, finalista, de que é tributária uma visão clássica da história -, poderíamos confrontá-la à passante de Asflores do mal, célebre encarnação poética da eterna transitoriedade do belo, tal como este é definido pelo poeta em $O$ pintor da vida moderna. ${ }^{18}$ Pois se não há nada além do transitório, do efêmero - das "sombras" -, o que é eterno é a potência de metamorfose, e toda forma

"[...] faute de savoir ce qui est écrit là-haut, on ne sait ni ce qu'on veut ni ce qu'on fait, et qu'on suit sa fantaisie qu'on appelle raison, ou sa raison qui n'est souvent qu'une dangereuse fantaisie qui tourne tantôt bien, tantôt mal." DIDEROT, Denis. Jacques le fataliste et son maître. Paris: Librairie Générale Française, 1972, p. 22.

17 "Qu'aperçois-je? Des formes? Des formes et quoi encore? Des formes. J'ignore la chose. Nous nous promenons entre des ombres, ombres nous-mêmes pour les autres et pour nous." DIDEROT, Denis. Éléments de physiologie. Paris: Librairie Marcel Didier, 1964, p. 307-8. 
estética que persevera como tal não é outra coisa senão um resto, um dejeto de luxo desse infinito processo de infinitização.

Talvez seja possível dizer que, para Baudelaire, se essa "coisa” que Diderot "ignora" por trás das formas que não cessam de se dissolver com suas próprias contingências, que se essa coisa se infinitiza, na iminência de seu desaparecimento, é por meio deste seu outro, deste seu resto que é justamente a forma estética. Como o ilustra essa espécie de eco tenaz dos famosos versos do poeta à passante apenas entrevista e já desaparecida na multidão, versos que celebram um amor e um presente que não cessam de não se consumar:

Um raio... e depois a noite! - Fugitiva beleza

Cujo olhar me fez subitamente renascer,

Não te verei mais senão na eternidade?

Em outro lugar, longe daqui! tarde demais! nunca talvez!

Pois ignoro para onde foges, não sabes para onde vou,

Ó tu que eu teria amado, ó tu que o sabias!

Un éclair... puis la nuit! - Fugitive beauté

Dont le regard mia fait soudainement renaître,

Ne te verrai-je plus que dans léternité?

Ailleurs, bien loin d'ici! trop tard! jamais peut-être!

Car j'ignore où tu fuis, tu ne sais où je vais,

O toi que jeusse aimé, ô toi qui le savais! $!^{19}$

Em diálogo com esse poema, diz o ensaísta André Hirt, num longo texto sobre Baudelaire: "Assim o Moderno é movimento. Baudelaire busca uma figura e encontra apenas o movimento tremido da forma na passagem. Pois a forma, diferentemente da figura, é passagem". ${ }^{\circ}$

Interessa-me especialmente aqui esse "movimento tremido da forma na passagem". Pois, a cada vez que se busca a figura na forma, o que se encontra é o movimento: o presente se querendo mais espesso, mais ele mesmo, mais próximo da "vitalidade uni-

19 Idem. As flores do mal, op. cit., p. 344-5.

20 HIRT, André. Il faut être absolument lyrique. Une constellation de Baudelaire. Paris: Kimé, 2000, p. 194-5. 
versal", mas sempre em diferendo com o infinito real da experiência - sua espessura. $\mathbf{O}$ que se encontra, como bem sabe o escultor Idéolus na busca de sua escultura, é sempre a des-figura: “... sempre, ainda mármore...., implicando a consciência de que a forma é sempre, ainda, passagem, sempre um disfarce - um esboço - do infinito, de que há sempre, memória virtual, uma espessura formal a espreitar-lhe os contornos. Razão pela qual a arte, desde o romantismo, primaria cada vez mais inarredavelmente pelo inacabamento, não como recusa da experiência do real, mas como procedimento que visa a seu (re)conhecimento como finito-infinito. O que, na leitura, por vir, implicará necessariamente a remontagem anacrônica...

Mas prefiro terminar com uma das belas imagens baudelairianas da forma do infinito: a do "infinito diminutivo", colhida em Meu coração desnudado:

Por que o espetáculo do mar é tão infinitamente e tão eternamente agradável? Porque o mar oferece a um só tempo a ideia da imensidão e do movimento. Seis ou sete léguas representam para o homem o raio do infinito. Eis um infinito diminutivo. O que importa se ele basta para sugerir a ideia do infinito total? ${ }^{22}$

Marcelo Jacques de Moraes é professor de Literatura Francesa da UFRJ e pesquisador do CNPq. Tem doutorado em Letras Neolatinas (UFRJ) e pós-doutorado em Literatura Francesa (Paris 8). Tem artigos publicados em livros e periódicos no Brasil e no exterior.

21 Idem, p. 469

22 "Pourquoi le spectacle de la mer est-il si infiniment et si éternellement agréable? Parce que la mer offre à la fois l'idée de l'immensité et du mouvement. Six ou sept lieues représentent pour l'homme le rayon de l'infini. Voilà un infini diminutif. Qu'importe s'il suffit à suggérer l'idée de l'infini total?" Idem, p. 636. André Hirt (Baudelaire. L'exposition de la poésie. Paris: Kimé, 1998) e Michel Deguy (Choses de la poésie et affaire culturelle. Paris: Hachette, 1986) fazem alusão a essa passagem. 